\title{
Radial basis Function Neural Network for Predicting Flow Bottom Hole Pressure
}

\author{
Medhat H A Awadalla \\ Dept. of Electrical and Computer Engineering, SQU, Oman \\ Dept. of Communications and Computers, Helwan University, Egypt
}

\begin{abstract}
The ability to monitor the flow bottom hole pressure in pumping oil wells provides important information regarding both reservoir and artificial lift performance. This paper proposes an iterative approach to optimize the spread constant and root mean square error goal of the radial basis function neural network. In addition, the optimized network is utilized to estimate this oil well pressure. Simulated experiments and qualitative comparisons with the most related techniques such as feedforward neural networks, neuro-fuzzy system, and the empirical model have been conducted. The achieved results show that the proposed technique gives better performance in estimating the flow of bottom hole pressure. Compared with the other developed techniques, an improvement of $7.14 \%$ in the root mean square error and $3.57 \%$ in the standard deviation of relative error has been achieved. Moreover, $90 \%$ and $95 \%$ accuracy of the proposed network are attained by $99.6 \%$ and 96.9\% of test data, respectively.
\end{abstract}

Keywords-Radial basis function neural network; neuro-fuzzy system; feedforward neural networks; empirical model

\section{INTRODUCTION}

Flowing bottom-hole pressure is the pressure that can be measured or calculated nearby the producing formation while the well is producing hydrocarbons. Petroleum engineers are keen to know the flowing bottom-hole pressure (FBHP) because it affects the productivity of oil wells, and helps in forecasting the potential of well throughout the well life cycle. In addition, it helps the optimization of artificial lifting performance, monitoring the performance of the well production, and monitoring sand conditions and conditions of the bore hole through the sand [1]. The appropriate gauges can be installed in the electric submersible pumping well systems to measure FBHP. Electric submersible pump systems, shown in Fig. 1, are the effective artificial lift method of pumping production fluids to the surface. However, to intervene the oil wells to measure FBHP is a tedious work, risky, and affects the wells production. Because of all these difficulties to measure the flowing bottom-hole pressure, the most common problems in the field of petroleum engineering is how to predict FBHP. Several trials have been accomplished by engineering and even tackled by research to find empirical correlations to predict this pressure. Not all of these trials managed to produce successful correlations that provide good prediction in some cases [2-4]. Different heuristic approaches have been used to tackle the problem of predicting FBHP such as Neural networks (NNs) [5-7]. Single and two layers neural networks have been developed. The parameters of the neural networks such as number of neurons per layer, and the error goal have been optimized. Neuro-fuzzy system has been introduced in [8], where the main mechanisms of fuzzy logic technique such as fuzzification, rule base, inference, and defuzzification have been implemented in the layers of the neural network. Particle Swarm optimization, PSO, and neuro-fuzzy models again are addressed the valuable problem [9-12]. Furthermore, support vector machine approach is used as a solution for predicating FBHP [13]. Even though these approaches succeeded with high extent of accuracy to be considered as rigid solutions for this viable problem. Many researches and engineers in the petroleum field are still looking forward for more robust solutions with high extent of accuracy. In this paper, radial basis function neural network is proposed to address this problem. Real data have been collected from different wells to be used as samples for learning and testing the developed network. To prove the effectiveness of the proposed radial basis function neural network in estimating FBHP, rigorous performance analysis have been conducted and a comparison with the most related approaches have been accomplished such as feedforward and neuro-fuzzy system, and the empirical model.

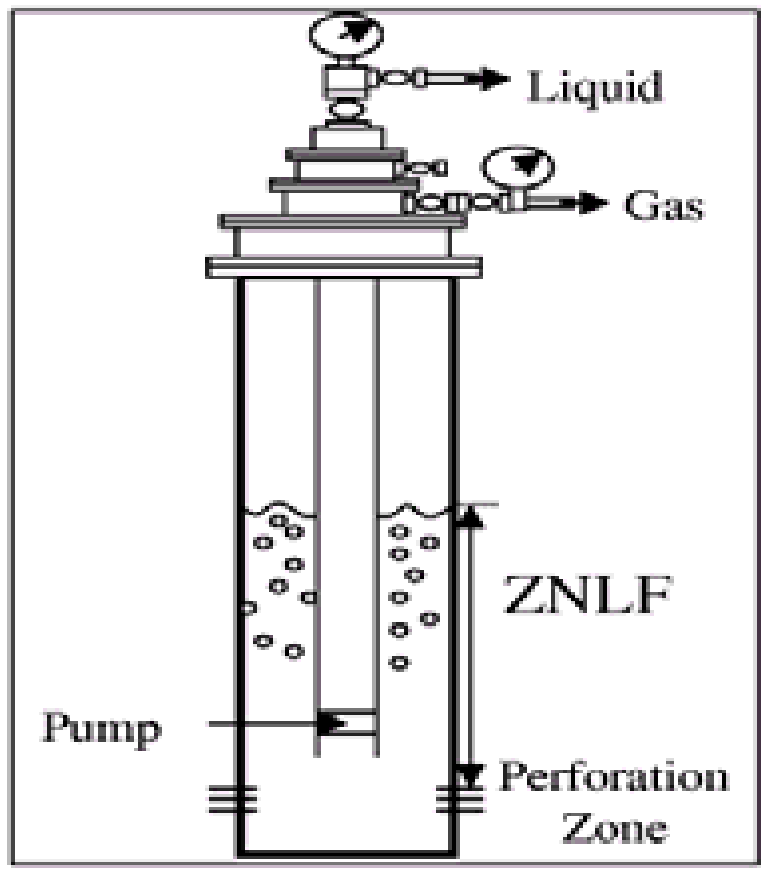

Fig. 1. Electric Submersible Pumping Oil Well System. 
The organization of the paper is as follows. Section 2 shows the data sources and collections. Some data samples are illustrated. These samples have been used for learning the proposed model and testing it. Radial basis function neural network is presented in Section 3. Optimization of RBFNN parameters are presented in Section 4. The experiments and discussions are demonstrated in Section 5. Section 6 has the paper conclusions.

\section{DATA SOURCES AND COLleCtions}

The data used for inputs (12 inputs) and the outputs (1 output) is obtained from different oil fields in Oman [6-8]. These different fields are shown in Fig. 2, where fields A, B, and $\mathrm{C}$ are considered here because they are the most valuable fields. All these fields have water injection as reservoir pressure support and all of them having well production with two different artificial lifting, ESP and gas-lift.

Some samples of the used data sets are given in Table 1 . Before initializing the training/testing of the model, the data sets should be randomized. In addition, before training/testing the developed model, normalization for the data using MATLAB toolbox normalizing function "mapminmax" has been made. At the end, when the phase of training and testing finished, de-normalization for the achieved data sets has been carried out to convert the data again to the wells and timing sequence. Table 2 shows the number of samples and the wells that have been used from the three fields. Table 3 and Table 4 show samples of the data elements for the three fields and for the case of all the three fields data combined.

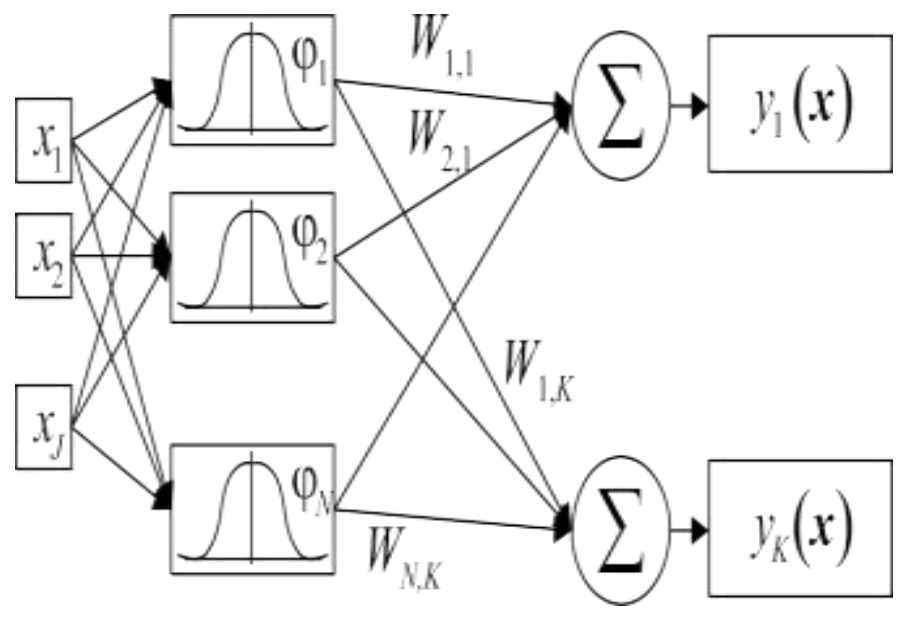

Fig. 2. The Three Fields Layout.

TABLE I. SAMPLE OF DATA USED

\begin{tabular}{|c|c|c|c|c|c|c|c|c|c|c|c|c|c|c|}
\hline$\stackrel{\mathscr{\Xi}}{\Xi}$ & 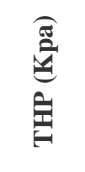 & 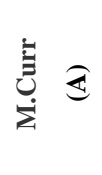 & 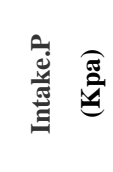 & 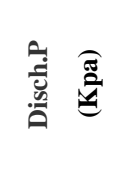 & 总 & $\bar{\sigma} \stackrel{\hat{m}}{\Xi}$ & 离 & 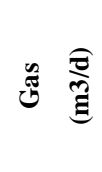 & 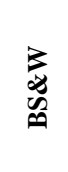 & ِّ & $\frac{\overline{3}}{\overline{0}}$ & $\begin{array}{l}\bar{\vdots} \\
\vdots \\
\bar{\omega} \\
\vdots \\
3\end{array}$ & 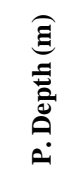 & इ \\
\hline $12 / 6 / 2012$ & $\begin{array}{c}3123 . \\
8\end{array}$ & 82.8 & 10398.6 & 18024.2 & 1149.9 & 61.3 & 1088.50 & 1349.6 & 94.6 & 22 & 37.2 & 1.13 & 1321 & $\begin{array}{c}\text { A05 } \\
9\end{array}$ \\
\hline $13 / 6 / 2012$ & $\begin{array}{c}3226 . \\
7\end{array}$ & 83 & 10385.5 & 18033.3 & 1149.9 & 61.3 & 1088.5 & 1349.6 & 94.6 & 22 & 37.2 & 1.13 & 1321 & $\begin{array}{c}\text { A05 } \\
9\end{array}$ \\
\hline $14 / 6 / 2012$ & $\begin{array}{c}3219 . \\
8\end{array}$ & 82 & 10380.8 & 18023.6 & 1149.9 & 61.3 & 1088.5 & 1349.6 & 94.6 & 22 & 37.2 & 1.13 & 1321 & $\begin{array}{c}\mathrm{A} 05 \\
9\end{array}$ \\
\hline $4 / 7 / 2012$ & $\begin{array}{c}3229 . \\
9\end{array}$ & 82.4 & 10356.1 & 18029.8 & 1335.7 & 14.6 & 1321 & 629 & 98.9 & 43 & 37.2 & 1.13 & 1321 & $\begin{array}{c}\mathrm{A} 05 \\
9\end{array}$ \\
\hline $5 / 7 / 2102$ & $\begin{array}{c}3265 . \\
5\end{array}$ & 82.4 & 10357.1 & 18051.6 & 1335.7 & 14.6 & 1321 & 629 & 98.9 & 43 & 37.2 & 1.13 & 1321 & $\begin{array}{c}\mathrm{A} 05 \\
9\end{array}$ \\
\hline $\begin{array}{c}30 / 12 / 201 \\
0\end{array}$ & $\begin{array}{c}1849 . \\
8\end{array}$ & 57 & 9431 & 16466 & 1595.6 & 51.6 & 1543.9 & 2247.1 & 96.7 & 43 & 40.4 & 1.12 & 1327 & $\begin{array}{c}\mathrm{A} 06 \\
5\end{array}$ \\
\hline $\begin{array}{c}31 / 12 / 201 \\
0\end{array}$ & $\begin{array}{c}1834 . \\
7\end{array}$ & 56.4 & 9393.6 & 16447 & 1595.6 & 51.6 & 1543.9 & 2247.1 & 96.7 & 43 & 40.4 & 1.12 & 1327 & $\begin{array}{c}\mathrm{A} 06 \\
5\end{array}$ \\
\hline $1 / 1 / 2011$ & $\begin{array}{c}1835 . \\
5\end{array}$ & 57 & 9381.2 & 16462.5 & 1290 & 46 & 1244 & 844 & 96.4 & 18 & 40.4 & 1.12 & 1327 & $\begin{array}{c}\mathrm{A} 06 \\
5\end{array}$ \\
\hline $2 / 1 / 2011$ & $\begin{array}{c}1839 . \\
3\end{array}$ & 57 & 9384 & 16475 & 1290 & 46 & 1244 & 844 & 96.4 & 18 & 40.4 & 1.12 & 1327 & $\begin{array}{c}\mathrm{A} 06 \\
5\end{array}$ \\
\hline
\end{tabular}


TABLE II. FIELDS DATA SAMPLES SUMMARY

\begin{tabular}{|c|c|c|c|c|c|}
\hline & & & \multicolumn{2}{|l|}{ Field-A } & \multirow[b]{2}{*}{ Average } \\
\hline & Input & Maximum & Minimum & Range & \\
\hline 1 & Tubing Head Pressure & 4733 & 527 & 4206 & 2191 \\
\hline 2 & Motor Current & 141 & 33 & 108 & 58 \\
\hline 3 & Liquid Production Rate & 1812 & 305 & 1507 & 941 \\
\hline 4 & Oil Production Rate & 62 & 4 & 58 & 28 \\
\hline 5 & Water Production Rate & 1769 & 272 & 1497 & 913 \\
\hline 6 & Gas Production Rate & 4800 & 59 & 4741 & 1494 \\
\hline 7 & Base Sediment \& Water (water cut) & 99 & 88 & 11 & 96 \\
\hline 8 & Formation Gas Oil Ratio & 657 & 3 & 654 & 59 \\
\hline 9 & Oil Specific Gravity & 40.4 & 37.0 & 3.4 & 37.7 \\
\hline 10 & Produced Water Specific gravity & 1.13 & 1.12 & 0.01 & 1.13 \\
\hline 11 & Pump Intake True Vertical Depth & 1481 & 896 & 585 & 1192 \\
\hline \multirow[t]{2}{*}{12} & Pump Discharge Pressure & 19140 & 10925 & 8215 & 15214 \\
\hline & Output & & & & \\
\hline \multirow[t]{3}{*}{1} & Pump Intake Pressure & 11703 & 3468 & 8235 & 7680 \\
\hline & & & \multicolumn{2}{|l|}{ Field-B } & \\
\hline & Input & Maximum & Minimum & Range & Average \\
\hline 1 & Tubing Head Pressure & 4980 & 506 & 4474 & 2043 \\
\hline 2 & Motor Current & 87 & 16 & 71 & 47 \\
\hline 3 & Liquid Production Rate & 1687 & 259 & 1429 & 829 \\
\hline 4 & Oil Production Rate & 98 & 1 & 97 & 26 \\
\hline 5 & Water Production Rate & 1655 & 258 & 1398 & 802 \\
\hline 6 & Gas Production Rate & 32562 & 80 & 32482 & 1897 \\
\hline 7 & Base Sediment \& Water (water cut) & 100 & 91 & 9 & 97 \\
\hline 8 & Formation Gas Oil Ratio & 1064 & 8 & 1056 & 99 \\
\hline 9 & Oil Specific Gravity & 40.4 & 32.8 & 7.6 & 38.9 \\
\hline 10 & Produced Water Specific gravity & 1.13 & 1.01 & 0.12 & 1.11 \\
\hline 11 & Pump Intake True Vertical Depth & 1199 & 909 & 290 & 1032 \\
\hline \multirow[t]{2}{*}{12} & Pump Discharge Pressure & 19370 & 10121 & 9249 & 14745 \\
\hline & Output & & & & \\
\hline \multirow[t]{3}{*}{1} & Pump Intake Pressure & 11358.2 & 2208.5 & 9149.7 & 6414.3 \\
\hline & & & \multicolumn{2}{|l|}{ Field-C } & \\
\hline & Input & Maximum & Minimum & Range & Average \\
\hline 1 & Tubing Head Pressure & 5850 & 382 & 5468 & 3130 \\
\hline 2 & Motor Current & 95 & 28 & 67 & 51 \\
\hline 3 & Liquid Production Rate & 1602 & 256 & 1345 & 602 \\
\hline 4 & Oil Production Rate & 32 & 2 & 30 & 11 \\
\hline 5 & Water Production Rate & 1582 & 250 & 1331 & 591 \\
\hline 6 & Gas Production Rate & 12747 & 61 & 12686 & 582 \\
\hline 7 & Base Sediment \& Water (water cut) & 100 & 93 & 7 & 98 \\
\hline 8 & Formation Gas Oil Ratio & 1437 & 6 & 1431 & 66 \\
\hline 9 & Oil Specific Gravity & 34.0 & 34.0 & 0.0 & 34.0 \\
\hline 10 & Produced Water Specific gravity & 1.13 & 1.10 & 0.03 & 1.10 \\
\hline 11 & Pump Intake True Vertical Depth & 1174 & 1147 & 27 & 1165 \\
\hline \multirow[t]{2}{*}{12} & Pump Discharge Pressure & 18870 & 9899 & 8971 & 14384 \\
\hline & Output & & & & \\
\hline 1 & Pump Intake Pressure & 14180.9 & 3487.4 & 10693.5 & 6031.0 \\
\hline
\end{tabular}


TABLE III. FIELDS A, B, AND C DATA SUMMARY

\begin{tabular}{|l|l|l|}
\hline & No. Wells & No. Data samples \\
\hline Field-A & 15 & 8560 \\
\hline Field-B & 19 & 11870 \\
\hline Field-C & 8 & 4680 \\
\hline
\end{tabular}

TABLE IV. ALL FIELDS DATA SUMMARY

\begin{tabular}{|c|c|c|c|c|c|}
\hline \multicolumn{6}{|c|}{ All Fields } \\
\hline & Input & $\begin{array}{l}\text { Maxim } \\
\text { um }\end{array}$ & $\begin{array}{l}\text { Minimu } \\
\mathrm{m}\end{array}$ & Range & $\begin{array}{l}\text { Avera } \\
\text { ge }\end{array}$ \\
\hline 1 & Tubing Head Pressure & 5850 & 382 & 5468 & 2273 \\
\hline 2 & Motor Current & 141 & 16 & 125 & 52 \\
\hline 3 & Liquid Production Rate & 1812 & 256 & 1556 & 825 \\
\hline 4 & Oil Production Rate & 98 & 1 & 97 & 24 \\
\hline 5 & Water Production Rate & 1769 & 250 & 1519 & 801 \\
\hline 6 & Gas Production Rate & 32562 & 59 & 32503 & 1548 \\
\hline 7 & $\begin{array}{l}\text { Base Sediment \& Water } \\
\text { (water cut) }\end{array}$ & 100 & 88 & 12 & 97 \\
\hline 8 & Formation Gas Oil Ratio & 1437 & 3 & 1434 & 81 \\
\hline 9 & Oil Specific Gravity & 40.4 & 32.8 & 7.6 & 37.7 \\
\hline $\begin{array}{l}1 \\
0\end{array}$ & $\begin{array}{l}\text { Produced Water Specific } \\
\text { gravity }\end{array}$ & 1.13 & 1.01 & 0.12 & 1.12 \\
\hline $\begin{array}{l}1 \\
1\end{array}$ & $\begin{array}{l}\text { Pump Intake True Vertical } \\
\text { Depth }\end{array}$ & 1481 & 896 & 585 & 1104 \\
\hline \multirow[t]{2}{*}{$\begin{array}{l}1 \\
2 \\
\end{array}$} & Pump Discharge Pressure & 19750 & 10458 & 9292 & 15104 \\
\hline & Output & & & & \\
\hline 1 & Pump Intake Pressure & 14180.9 & 2208.5 & $\begin{array}{l}11972 \\
.3\end{array}$ & 6745.2 \\
\hline
\end{tabular}

\section{Radial basis Function Neural Network}

Radial Basis Neural Network, RBFNN, is a powerful, fast learning, and self-organized neural network. It is better than Back Propagation (BP) network in approximation, classification and learning speed, especially in processing highly nonlinear problems [14-15]. Fig. 3 illustrates the structure of RBFNN, where the first layer represents the input layer. The second layer is the hidden radial basis layer, and the last layer represents the output linear layer.

The input layer can be considered as gate for the inputs $\mathrm{x}=$ $(\mathrm{x} 1, \mathrm{x} 2, \ldots, \mathrm{xJ})$, where the number of inputs is represented by $\mathrm{J}$. There is a full connection among the input neurons and the hidden layer neurons, the links that used to connect them have no weights. The number of neurons in the hidden layer, $\mathrm{N}$, is variable and this number can be optimized through the process of training. The activation functions within the hidden layer neurons are a nonlinear radial basis function such as Gaussian function shown in equation 1 .

$\varphi_{n}(x)=e^{-\beta\left\|x-\mu_{n}\right\|^{2}}$

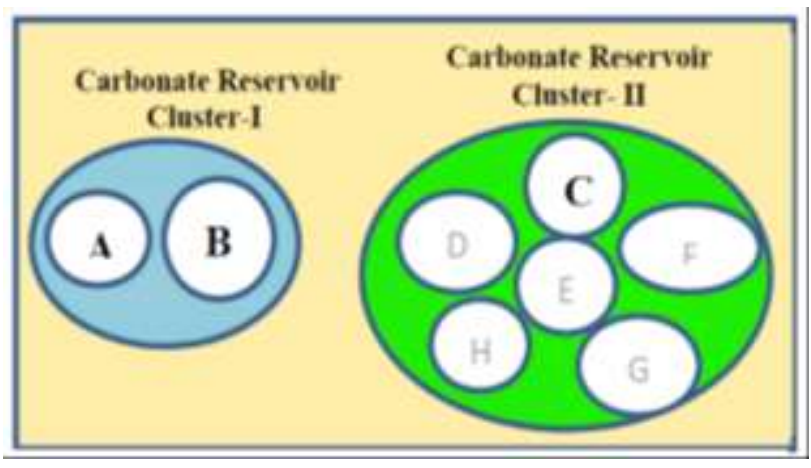

Fig. 3. Radial basis Function Neural Network Structure.

Where $\mathrm{x}$ is the input vector, $\mu$ is the prototype vector, $\|$.$\| is$ Euclidean distance, and $\beta$ is the spread parameter. The distance between the inputs $\mathrm{x}$ and the prototypes $\mu,(\mu 1, \mu 2$, $\ldots, \mu \mathrm{N})$ control the activation of the neurons in the hidden layer. The output of each neuron takes a value between 0 and 1 and the maximum value is 1 in the case of both the prototype and neuron input values are equal. The output of the hidden layer neurons are weighted and linearly summed to produce the output for every element $y_{k}$ in the output vector $\mathrm{y}(\mathrm{x})=(\mathrm{y} 1, \mathrm{y} 2, \ldots, \mathrm{yk})$, as shown in equation 2 .

$y_{k}(x)=\sum_{n=1}^{N} w_{n, k} \cdot \varphi_{n}(x)$

MATLAB Toolbox functions such as newrbe and newrb can be used to design the radial basis function neural networks. At the starting, there are no neurons in the hidden radial basis (radbas) layer; and then, the function newrb will add one neuron at a time iteratively. For every iteration, the input vector that results in reducing the error of the network is the most used to add a radbas neuron. In addition, if the error of the new developed network is small enough (less than a specified value), newrb function will not generate more neurons. Otherwise, the next neuron will be added. More neurons will be added to the hidden layer of a radial basis network until it reaches the desired mean squared error goal or the maximum number of neurons.

In addition to the input and output (targets) training data sets, the newrb takes two arguments, the first one is the sumsquared error goal and the second is the spread constant (factor). The spread constant plays an important role in the development of the radial basis function neural network.

Many neurons are required to fit fast-changing function for big values of the spread factor (vicinity of 1 ). While for small values of spread factor (vicinity of 0 ), many neurons are required to fit a smooth function. This behavior poses restriction in generalizing the network. Using 'newrb' iteratively with various spreads analyzing the achieved results to determine the optimum values for these arguments.

\section{Radial basis Function NeURAl Network PARAMERS OPTIMIZATION}

In this section, the root mean square error goal and the spread value of the radial basis function neural network are optimized in such way that the radial basis neural network will provide its best performance. 
Starting with a very basic structure, with default spread value for the radial function of 1 , has maximum number of neurons of 150 with 2 neurons are added every iteration and the mean square error goal of 0.0001 . Then, the mean square error goal is doubled in 20 steps until 0.004. Each time, the network is trained to the specified training error goal. After each training, the network is tested using test data that is not been used in the training phase. The network performance statistical indicators are recorded; the main performance indicator considered is the Relative Root Mean Square Error (RMSE) of the test data. In addition, the percentages of the test data attained 95\% and 90\% accuracy of FBHP estimation are used as a secondary performance indicator. Fig. 4 shows the network performance indicators against the mean square error goal. The best point for the RMSE is the point with minimum value whereas for the percentage of the test data with $90 \%$ and $95 \%$ accuracy is the maximum value. It clear that the best point is the point with $0.6 \times 10^{-3}$ mean square error goal. With polynomial fitting for the RMSE data, it is clear that the best point from the polynomial fit is at $1.5 \times 10^{-3}$. The two best points are far apart so, further tuning and improvements of the selected error goal are carried out by running the model with varying error goal from $0.2 \times 10^{-3}$ to 2 $\mathrm{x} 10^{-3}$. The results are shown in Fig. 5. It can be seen that the best point of the RMSE is $3.1 \%$ at a mean square error training goal of $0.8 \times 10^{-3}$. In addition, the average of absolute error accuracy of the model results might be observed from the percent of the test data that came up with intake pressure estimations within the 5\% and $10 \%$ error band from the actual intake pressure measurements are $90.8 \%$ and $98.9 \%$ respectively. With the RMSE polynomial fit, it is obvious that the best point occurs at an error goal of $0.7 \times 10^{-3}$, which is very close to the actual RMSE. Therefore, a value of $0.7 \times 10^{-3}$ is selected to be the best mean square error goal.

Further improvements of the model are carried out by selecting the best value for the spread constant that would result with the best network performance. It is happened by training the network with the selected best mean square error goal of $0.7 \times 10-3$ and different values of spread constant starting from 0.2 and increasing to 40 , the achieved results are depicted in a Fig. 6.
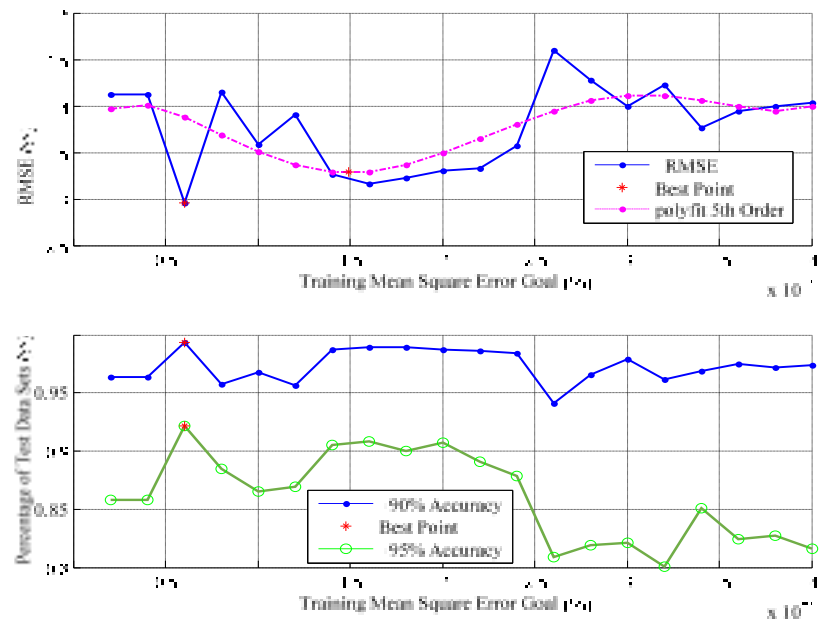

Fig. 4. RMSE and Accuracy of RBNN with Spread=1 vs. Training Error Goal.
As shown in Fig. 6, the best performance point is at the very low range of the spread value from 0 to 1 . The results show that the best point is at a spread constant value of 0.4 . To get the picture clearer and to zoom in, another optimization run is carried out with spread constant varying from 0.1 to 1.0 with step of 0.1 and again the performance trends is shown in Fig. 7.
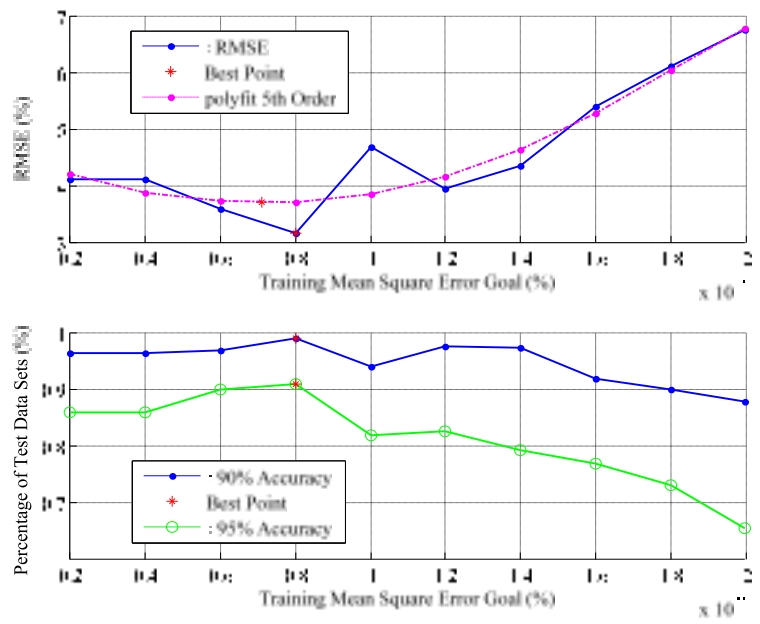

Fig. 5. RMSE and Accuracy of RBNN with Spread=1 vs. Training Error Goal.
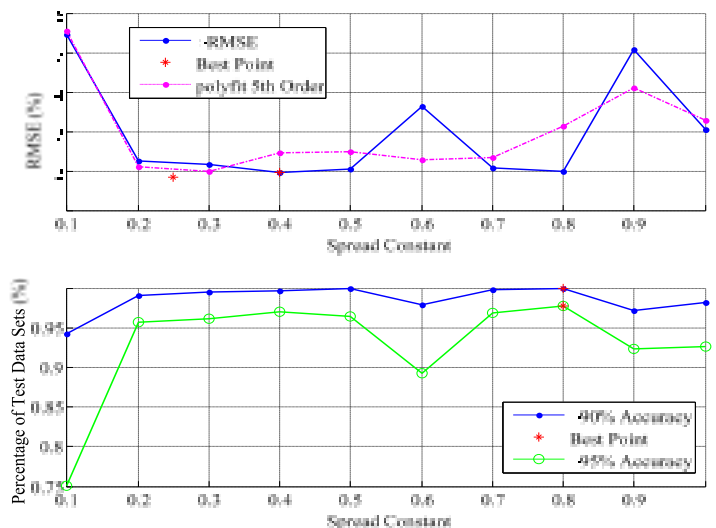

Fig. 6. RMSE and Accuracy of RBNN with Error Goal=0.7 x10-3 vs. Spread Constant.
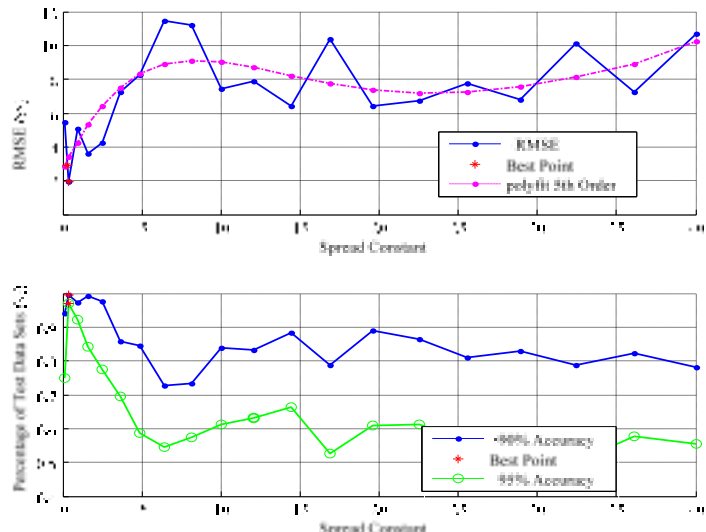

Fig. 7. RMSE and Accuracy of RBNN with Error Goal=0.7 x10-3 vs Spread Constant. 
As illustrated in Fig. 7, the best spread constant is within the range of 0.2 to 0.5 . The best RMSE is $1.93 \%$ at a spread constant value of 0.4 . This is also, supported by the good accuracy points of $99.6 \%$ of test data fall within the $10 \%$ error band and $96.9 \%$ fall within the 5\% error band. Therefore, the final best architecture of the radial basis neural network is the one with $0.7 \times 10^{-3}$ mean square error goal, spread constant of 0.4 and a number of neurons of 126 .

\section{EXPERIMENTAL RESULTS AND DISCUSSIONS}

Extensive experiments have been carried out using data collected from real oil wells to compare the performance of the developed radial basis function neural network with neurofuzzy system, two-layer feedforward neural network. Root Mean Square Error (RMSE), Standard Deviation (STD), Correlation Coefficient (R), and the accuracy have been used as performance metrics for the comparison. The following equations have been used to determine the mentioned performance metrics.

The average Relative Error $E_{r}$ is calculated using the following equation:

$E_{r}=\frac{1}{n} \sum_{i=1}^{N} E_{i}$

Where, $E_{i}$ is the relative deviation of the estimated value from the measured one and is calculated as:

$E_{i}=\left[\frac{(F B H P)_{\text {meas }}-(F B H P)_{e s t}}{(F B H P)_{\text {meas }}}\right] X 100$

Where: $(F B H P)_{\text {meas }}$ is the actual measured value of the $F B H P$ and $(F B H P)_{e a t}$ is the estimated value.

Average Absolute Relative Error $E_{a}$ is calculated using the following equation:

$E_{a}=\frac{1}{n} \sum_{i=1}^{N}\left|E_{i}\right|$

Root Mean Square Error RMSE is calculated using the following equation:

$R M S E=\left[\frac{1}{n} \sum_{i=1}^{N} E_{i}^{2}\right]^{0.5}$

Standard Deviation STD is calculated using the following equation:

$S T D=\sqrt{\frac{1}{m-n-1} \sum_{i=1}^{m}\left[\left\{\frac{F B H P_{\text {meas }}-F B H P_{\text {est }}}{F B H P_{\text {meas }}}\right\} X 100\right]^{2}}$

Where: $m-n-1$ represents the degree of freedom in multiple-regression.

The Correlation Coefficient $\mathrm{R}$ is calculated using the following equation:

$R=\sqrt{1-\frac{\sum_{i=1}^{n}\left[F B H P_{\text {meas }}-F B H P_{\text {est }}\right]}{\sum_{i=1}^{n} F B H P_{\text {meas }}-\frac{1}{n} \sum\left[\left\{F B H P_{\text {meas }}-F B H P_{\text {est }}\right\}\right]_{i}}}$

Fig. 8-11 show the achieved results. Based on the achieved results, the developed radial basis function neural network has a reasonable performance as two-layer feedforward neural network and outperforms the neuro-fuzzy system.

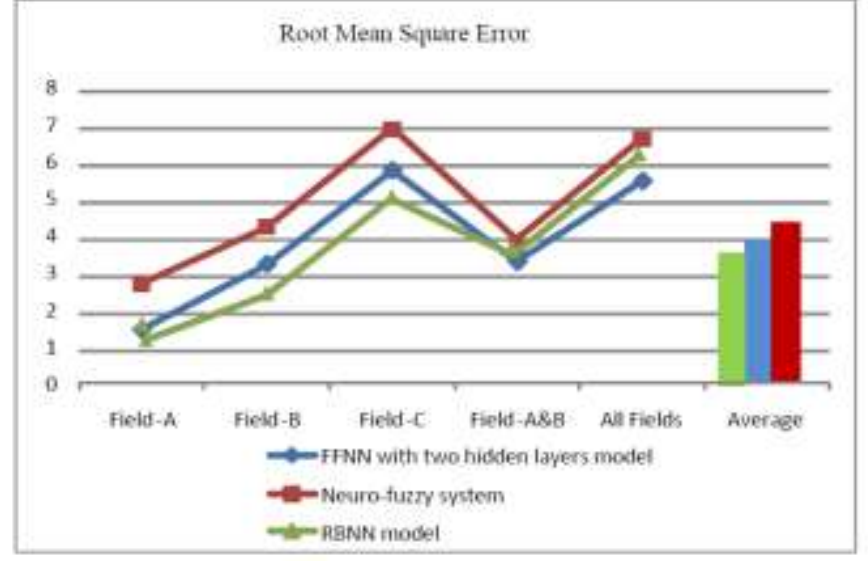

Fig. 8. The Achieved RMSE using RBFNN, FFNN, and Neuro-Fuzzy.

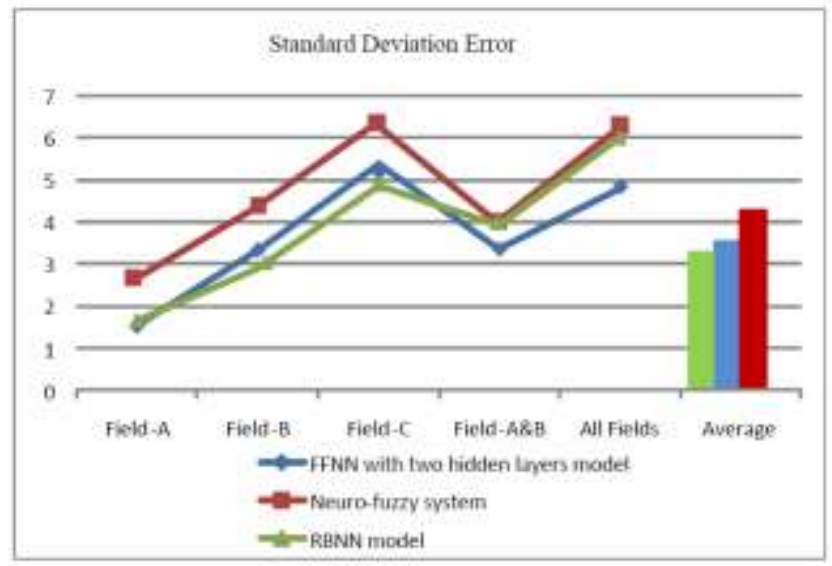

Fig. 9. The Achieved STD using RBFNN, FFNN, and Neuro-Fuzzy.

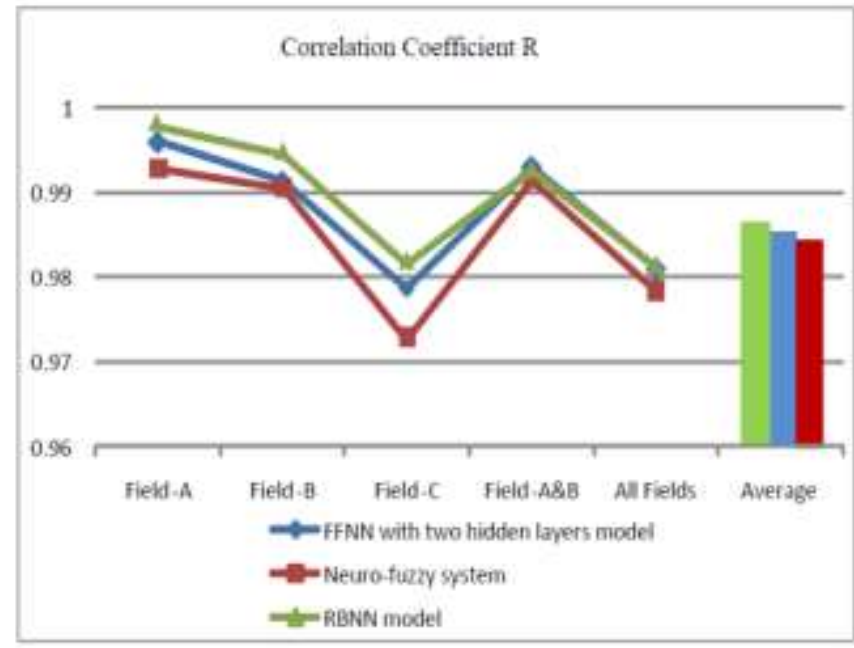

Fig. 10. The Achieved Correlation Coefficient using RBFNN, FFNN, and Neuro-Fuzzy.

For more validity test for the proposed architecture, a comparison has been accomplished with empirical model [16]. As shown in Fig. 12, all approaches outperform the empirical model especially radial basis neural network and feedforward neural network have remarkable results. 


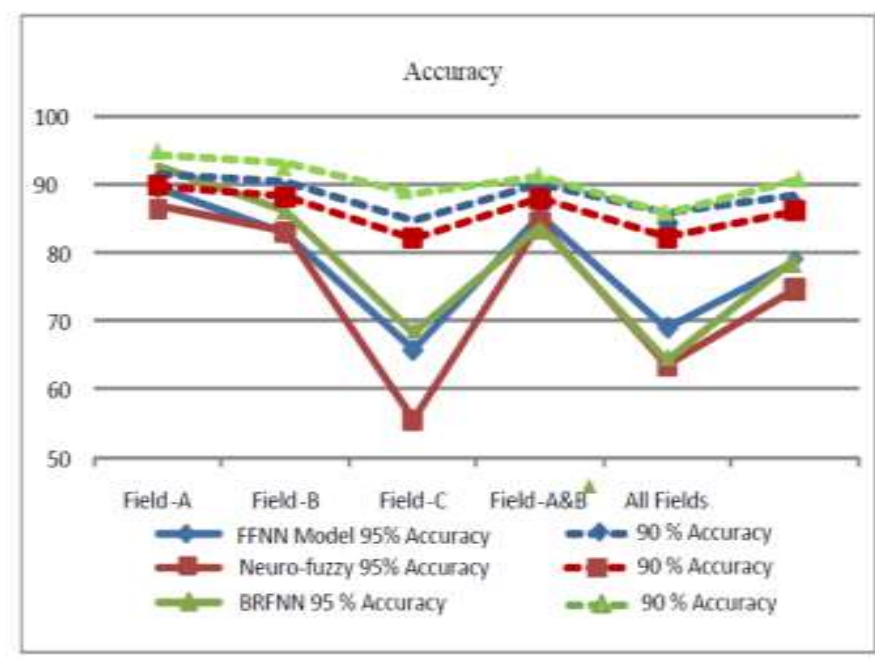

Fig. 11. Trends of RBFNN, FFNN and Neuro-Fuzzy Models Results for $\mathrm{A} / \mathrm{B} / \mathrm{C}$ Fields.

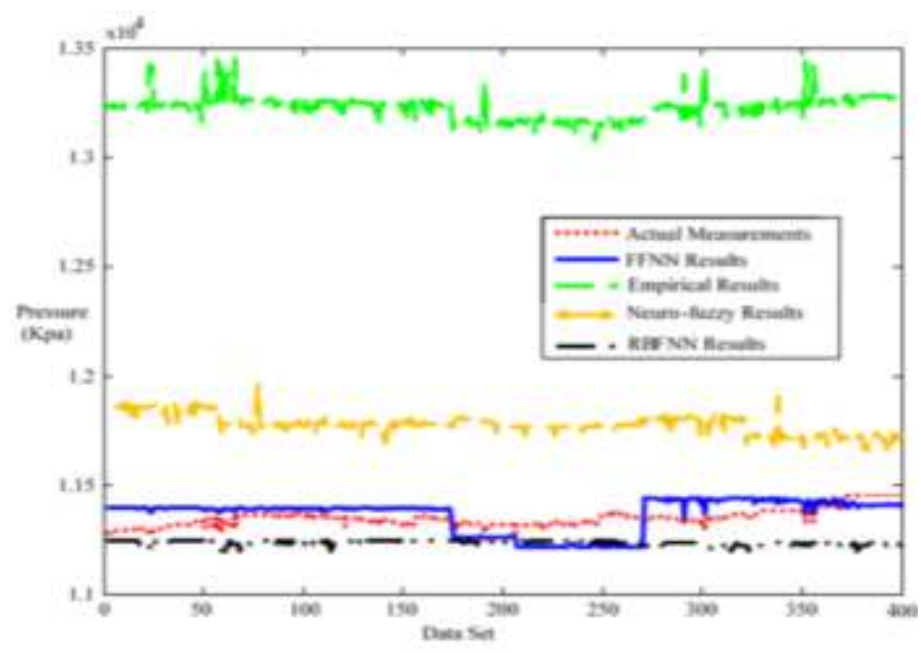

Fig. 12. Performance Comparison among RBFNN, Neuro-Fuzzy, FFNN, and Empirical Model.

\section{CONCLUSIONS}

This paper has proposed and developed radial basis function neural network to predict FBHP of oil wells. Spread factor and mean square error goal have been optimized for radial basis function neural network. The achieved results of the developed network are compared with two-layer neural network feedforward, neuro-fuzzy system, and the empirical model. The performance of the developed RBFNN is comparable with two-layer feedforward neural network and better than neuro-fuzzy system and the empirical model in terms of performance indicators, RMSE, STD, Correlation coefficient R, and the accuracy. An improvement of 7.14\% in the root mean square error, $3.57 \%$ in the standard deviation of relative error is achieved. Moreover, the accuracy of $90 \%$ and $95 \%$ are obtained by $99.6 \%$ and $96.9 \%$ of test data respectively. For further work, the remarkable capabilities of deep learning approaches will be invoked to achieve more accuracy in predicating FBHP.

\section{REFERENCES}

[1] S. Breit and N. Ferrier, "Using ESP systems for artificial lift". Pumps and Systems, April 2008.

[2] M. Ahmadi, M. Galedarzadeh, S. Shadizadeh. "Low parameter model to monitor bottom hole pressure in vertical multiphase flow in oil production wells". Petroleum 2 (2016) pp. 258-266.

[3] O. Adewale, "Optimization of natural gas field development using artificial neural networks" MSc Paper, The Pennsylvania State University, USA, 2010.

[4] O. Adekomaya, A.S. Fadairo, and O. Falode, "Predictive Tool for Bottom-Hole Pressure in Multiphase Flowing Wells" Petroleum \& Coal, ISSN 1337-7027, 50 (3), pp. 67-73, 2008.

[5] I. Jahanandish, B. Salimifard, and H. Jalalifar, "Predicting bottomhole pressure in vertical multiphase flowing wells using artificial neural networks" Journal of Petroleum Science and Engineering, vol. 75, pp. 336-342, 2011.

[6] M. Awadalla, H. Yousef, "Neural Networks for Flow Bottom Hole Pressure Prediction". International Journal of Electrical and Computer Engineering (IJECE), Vol. 6, No. 4, August 2016.

[7] M. Awadalla, H. Yousef, A. Al-Hinai, A. Al-Shidani, "Prediction of Oil Well Flowing Bottom-hole Pressure in Petroleum Fields", Sixth IEEE International Conference on Industrial Engineering and Operations Management, Kuala Lumpur, March 8-10, 2016.

[8] Awadalla, M., Yousef, H., and Al-Hinai, A.. A soft Computing Technique for Predicting Flow Bottom Hole Pressure. International Conference on Communication, Management and Information Technology, Madrid, Spain, 2018.

[9] M.A., Ahmadi, A., Bahadori, "Determination of oil well production performance using artificial neural network (ANN) linked to the particle swarm optimization (PSO) tool Petroleum" http://dx.doi.org/10.1016/j.petlm, 2015.

[10] D. Himansu, N. Ajay, N. Bighnaraj, H. S. Behera, "A Novel PSO Based Back Propagation Learning-MLP (PSO-BPMLP) for Classification. Proceedings of the International Conference on CIDM, pp. 461-471, 2014.

[11] M.A., Ahmadi, A., Bahadori, "Determination of oil well production performance using artificial neural network (ANN) linked to the particle swarm optimization (PSO) tool Petroleum" http://dx.doi.org/10.1016/j.petlm, 2015.

[12] J. A. Farrell and M. M. Polycarpou, Adaptive Approximation Based Control: Unifying Neural, Fuzzy and Traditional Adaptive Approximation Approaches. Wiley-Interscience, 2006.

[13] W. Chen, D. QF, F. Ye, J N Zhang, WC Wang. "Flowing bottom hole pressure prediction for gas wells based on support vector machine and random samples selection". International Journal of Hydrogen Energy, Vol.42, No.29, 18333-18342, 2017.

[14] M. Michalikova, M. Prauzek, J. Koziorek. "Impact of the Radial Basis Function Spread Factor onto Image Reconstruction in Electrical Impedance Tomography". IFAC-PapersOnLine 48-4 (2015), pp. 230233.

[15] H. Wang, X. Xu, "Applying RBF Neural Networks and Genetic Algorithms to Nonlinear System Optimization”, In Proceeding of the second International Conference on Materials and Products Manufacturing Technology, 2012, pp. 2457-2460.

[16] S. Bikbulatov, M. Khasanov, A. Zagurenko. Flowing Bottom hole Pressure Calculation for a Pumped Well under Multiphase Flow. Retrieved June 2013, from Cornell University Library. http://arxiv.org/abs/physics/0504083. 